\title{
O uso da entrevista na pesquisa-intervenção participativa em saúde mental: o dispositivo GAM como entrevista coletiva
}

\author{
The use of interviews in participative intervention and research: \\ the GAM tool as a collective interview
}

Christian Sade ${ }^{1}$

Leticia Maria Renault de Barros ${ }^{2}$

Jorge José Maciel Melo ${ }^{2}$

Eduardo Passos ${ }^{2}$

\footnotetext{
${ }^{1}$ Faculdade de Psicologia, Universidade Salgado de Oliveira. R. Marechal Deodoro 263, Centro. 24.030-060 Niterói RJ. christiansadevas@yahoo.com.br ${ }^{2}$ Departamento de Psicologia, Universidade Federal Fluminense.
}

\begin{abstract}
This paper seeks to assess a way of conducting interviews in line with the ideology of Brazilian Psychiatric Reform. In the methodology of participative intervention and research in mental health, the interview is less a data collection than a data harvesting procedure. It is designed to apply the principles of psychosocial care, autonomy as the basis for treatment, the predominance of the users and of their social networks and civic participation. Inspired by the Explicitation Interview technique, the contention is that the handling of the interview presupposes an open attitude able to promote and embrace different viewpoints. This attitude makes the interview a collective experience of sharing and belonging, allowing participants to reposition themselves subjectively in treatment with the emergence of groupality. As an example of using the interview as a methodological tool in mental health research, we examine research into adaptation of the tool of Autonomous Medication Management (GAM). It is an interventionist approach guided by principles that foster autonomy and the protagonist status of users of psychotropic medication, their quality of life, their rights and recognition of the multiple significances of medication, understood here as a collective interview technique.
\end{abstract}

Key words Interview, Methodology, Psychiatric reform, Participation, Intervention and research
Resumo O artigo propõe-se a discutir um modo de fazer entrevista em sintonia com o ideário da Reforma Psiquiátrica brasileira. Na metodologia de uma pesquisa-intervenção participativa da saúde mental, a entrevista é um procedimento menos de coleta do que de colheita de dados; voltada ao cultivo dos princípios da atenção psicossocial, da autonomia como direção do tratamento, do protagonismo do usuário e de sua rede social e de sua participação cidadã. Inspirados na técnica da entrevista de explicitação, entendemos que o manejo da entrevista supõe uma atitude de abertura capaz de promover e acolher diferentes pontos de vista. Tal atitude faz da entrevista uma experiência coletiva, de compartilhamento e de pertencimento, permitindo que os participantes se reposicionem subjetivamente e que haja a contração de grupalidade. Como exemplo do emprego da entrevista como ferramenta metodológica na investigação em saúde mental é citada a pesquisa de adaptação do dispositivo Gestão Autônoma da Medicação (GAM). É uma abordagem de intervenção norteada por princípios que valorizam a autonomia e o protagonismo dos usuários de psicofármacos, a sua qualidade de vida, os seus direitos e o reconhecimento das significações plurais da medicação e entendido aqui como uma prática de entrevista coletiva.

Palavras-chave Entrevista, Metodologia, Reforma psiquiátrica, Participação, Pesquisa-intervenção 


\section{Introdução}

O uso de entrevistas em pesquisas no campo da saúde mental não pode ser pensado sem considerar o que buscamos com a investigação. O desafio, em uma investigação que se pretende pesquisa-intervenção ${ }^{1,2}$, é levar a sério o seu caráter performativo na criação e no desenvolvimento das técnicas de pesquisa. Trabalhos como os de Despret $^{3}$, Latour ${ }^{4}$ e Stengers ${ }^{5}$ vêm demonstrando como a produção de conhecimento é inseparável da produção de realidade, afirmando que as práticas de pesquisa intervêm no campo pesquisado. Essa também é a direção indicada pelos institucionalistas franceses ao afirmarem que transformamos para conhecer a realidade e não o inverso, acentuando a dimensão política da pesqui$\mathrm{sa}^{6,7}$. A inseparabilidade entre conhecer e fazer, entre pesquisar e intervir, põe em questão os ideais de objetividade e neutralidade do conhecimento, apontando para o fato de que este sempre é produzido em um campo de implicações cruzadas. Na medida em que pesquisar não é representar, mas intervir na realidade, o desenvolvimento de nossos métodos de investigação não pode se furtar ao fato de que o pesquisador está sempre implicado com o campo de conhecimento. O desafio é assumir o caráter performativo das técnicas de entrevista, tendo em conta os seus efeitos sobre o objeto e cuidando desses efeitos.

Ao afirmarmos que entrevistar é intervir, entendemos que o procedimento metodológico é o de "colheita de dados", o que destaca o caráter produtivo, mais do que representativo, da pesquisa. A entrevista como procedimento de pesquisa-intervenção colhe dados porque cultiva a realidade no ato de conhecê-la. Tal cultivo pressupõe a dupla direção metodológica de acompanhar a experiência dos sujeitos na situação de entrevista e cuidar dos efeitos do procedimento de colheita de dados. Sendo assim, as questões que se colocam são: 1) O que queremos cultivar? Qual é a direção da pesquisa-intervenção e como tal direção orienta o procedimento da entrevista? 2) Como cultivar? Quais os modos de fazer para alcançar os objetivos pretendidos?

Nosso objetivo neste texto não é propor regras ou protocolos de entrevistas a serem seguidos como um modelo para pesquisas no campo da saúde. Propomo-nos a discutir o modo de fazer entrevista em sintonia com o ideário da Reforma Psiquiátrica brasileira, que defende os princípios da atenção psicossocial, a autonomia como direção do tratamento, o protagonismo do usuário e de sua rede social na constituição dos projetos terapêuticos e a ampliação da participação cidadã dos usuários dos serviços substitutivos ao manicômio. Interessa-nos pensar a entrevista nas pesquisas-intervenção do campo da saúde mental, tomando-a como procedimento menos de coleta do que de "colheita de dados". Quais são os objetivos da entrevista como "colheita de dados" no campo da saúde mental? Como a entrevista pode estar afinada com as práticas da saúde mental, de forma a favorecêlas? Como afinar o "modo de fazer" entrevista com os objetivos da reforma psiquiátrica? Queremos abordar essas questões tomando a situação específica da relação dos usuários dos serviços de saúde mental com os psicofármacos. Uma pesquisa em torno do tema da gestão autônoma da medicação (GAM) nos servirá de situação concreta para discutirmos o emprego da entrevista como ferramenta metodológica na pesquisa em saúde mental.

\section{Inflexão da entrevista nas práticas em saúde mental}

A entrevista é, frequentemente, tomada como ferramenta metodológica privilegiada para a investigação do ponto de vista dos sujeitos e apreender a experiência do outro ${ }^{8-10}$. Recorre-se à ela quando se acredita que para compreender certo comportamento social é preciso considerar o ponto de vista ou a perspectiva dos atores sociais que o vivenciam, ou seja, o sentido que eles mesmos conferem às suas ações. Fontanella et al. ${ }^{11}$, por exemplo, atribuem às entrevistas o objetivo de melhor conhecer o que as pessoas sentem e imaginam sobre os fenômenos da saúde, permitindo que os entrevistados falem sobre os significados que eles atribuem a suas experiências de vida e da doença. Entretanto, tendo em vista a nossa aposta na sintonia entre a metodologia de pesquisa e os desafios do campo da saúde mental, parece-nos insuficiente que a entrevista se limite à investigação dos pontos de vista apresentados face ao tema abordado.

A reforma psiquiátrica brasileira, afinada com os princípios do Sistema Único de Saúde (SUS) e com sua aposta na humanização das práticas de atenção e de gestão do processo de trabalho em saúde, aponta para a importância de se reconhecer e valorizar as experiências dos sujeitos implicados nos processos de produção de saúde. A experiência pessoal, no entanto, não pode ser tomada como um fim em si mesma, pois as políticas públicas em saúde a partir do SUS tomam o objeto de suas intervenções como uma realidade 
coletiva e não estritamente pessoal. Podemos, então, dizer que há uma diretriz de coletivização para os serviços públicos de saúde ${ }^{12,13}$.

A reforma psiquiátrica mudou a lógica do tratamento em saúde mental. A cura deixou de ser o alvo principal das ações de cuidado, as quais se voltaram para a existência concreta dos usuários dos serviços de saúde em sua relação com o território, pensado como rede de interdependências ou campo social. Quando dizemos que o CAPS tem uma ação psicossocial é porque o cuidado se dá neste limiar entre o individual e o coletivo. Foi nesta experiência-limiar que o movimento da reforma psiquiátrica fez a sua aposta e é aí que os serviços substitutivos devem afinar os seus dispositivos de intervenção. Esta ideia reaparece no cenário atual das políticas públicas de saúde como compromisso com "os valores de autonomia e protagonismo dos sujeitos, de corresponsabilidade entre eles, de solidariedade dos vínculos estabelecidos, dos direitos dos usuários e da participação coletiva no processo de gestão" ${ }^{14}$. Tal aposta na participação altera o processo de trabalho em saúde, afirmando seu caráter cogestivo ${ }^{15}$.

Um dos pontos de entrave da reforma psiquiátrica brasileira tem sido a utilização pouco crítica dos medicamentos psiquiátricos. O problema é menos o do uso ou não dos psicofármacos, mas o modo como têm sido prescritos, com pouca ou nenhuma inclusão dos usuários nas decisões do tratamento. A participação destes restringe-se, muitas vezes, à mera informação de seus sintomas e a alguns esclarecimentos acerca da prescrição medicamentosa. Como fomentar espaços de participação e de protagonismo compartilhado nas instituições de saúde? O desafio é o da criação de condições para uma mudança de atitude, para a alteração da maneira como os diferentes sujeitos se engajam no processo de produção de saúde. No caso da medicação, interessa que o usuário, mais do que apenas falar o que está sentindo ou pensando, tenha a sua experiência reconhecida e valorizada de modo que ela possa contar efetivamente para a gestão do tratamento. A mudança de atitude almejada pressupõe que os usuários e os diferentes profissionais dos serviços de saúde mental possam compartilhar experiências, para protagonizarem ações comuns, para coletivizarem questões que, de um modo ou de outro, a todos afeta.

Esse compartilhamento requer que possamos ir além das vivências pessoais em prol de uma experiência coletiva. Contudo, esse movimento não pode prescindir das vivências pessoais. Re- quer a promoção de modos coletivos de relação com as vivências e representações pessoais, ensejando o deslocamento entre pontos de vista distintos. A coletivização da experiência se faz a partir do processo que F. Guattari designou de transversalidade $^{16,17}$. Transversalidade se distingue tanto da horizontalidade, que organiza corporativamente os iguais, quanto da verticalidade, que hierarquiza os diferentes. Transversalizar é colocar lado a lado os diferentes, criando uma dinâmica de diferenciação que permite que as vivências e representações pessoais ganhem caráter processual, transformando-se sem se anularem nem se fecharem em perspectivas totalizantes. A transversalidade dos grupos atesta o seu grau de autonomia. É tão mais autônomo o grupo quanto maior for a sua abertura para a diferença intra e intergrupos. Nesse sentido, a autonomia das ações de gestão e cuidado no campo da saúde mental, contrariamente ao que se poderia pensar como individualização, corresponde justamente a uma transversalização dessas práticas pelo coletivo.

O conceito de autonomia tem uma polivocidade no campo da saúde ${ }^{18}$ que exige que definamos o sentido com o qual trabalhamos. Etimologicamente, autonomia remete ao processo de dar a si mesmo suas próprias regras (auto = próprio + nomia $=$ regras). No ato de dar a regra a si próprio pode se supor uma separação entre uma instância que dá a regra e outra que a ela se conforma. Assim, parte-se aquele que se diz autônomo em dois: um "onde se instalaria toda a espontaneidade que a atividade de legislar implica, e outro, onde se localizaria toda a docilidade, para não dizer passividade, que implica a atividade de se conformar à lei dada"19. Para evitar uma concepção de autonomia que traria embutido um sentido de heteronomia, é preciso tomar a autonomia como criação simultânea do sujeito e das regras de seu funcionamento. Nesse sentido, as regras de um sistema autônomo não podem ser entendidas como imperativo heteronômico, mas expressão da relação criativa do sujeito com o seu território existencial. A autonomia se realiza, portanto, na relação de coemergência entre sujeito e mundo, sendo, por definição, uma autonomia relacional ou coletiva. Rompe-se, assim, com a concepção de autonomia como individualidade e autossuficiência, livre arbítrio e independência. Por autonomia entendemos o funcionamento de uma rede de inter-relações e codependências ${ }^{20}$ que gera suas regras de funcionamento.

É com essa aposta ético-politica na coletivização que queremos pensar a prática de entrevista. 
Por isso, ela não pode se limitar à detecção dos pontos de vista apresentados face ao tema abordado, tampouco ignorá-los. A entrevista pode ser um procedimento que ajuda na promoção de modos mais autônomos e coletivos de relação com esses pontos de vista, o que equivale a transformá-los. A entrevista pode intervir e cultivar a experiência ao investigá-la, não estando necessariamente voltada para a busca de respostas a questões pré-estabelecidas. Pode ser um procedimento para a produção e a coletivização das questões investigadas, ensejando novos sentidos, produzindo diferenciações, traçando novas linhas de conversa, promovendo agenciamentos com vozes de coletivos até então inaudíveis ${ }^{21}$. Como o uso de entrevista numa pesquisa que almeja ser interventiva e participativa sobre a experiência da medicação pode contribuir para fomentar uma gestão mais autônoma e coletiva do uso do medicamento? Não basta que a entrevista acesse uma multiplicidade de questões que afetam usuários, familiares e profissionais dos Centros de Atenção Psicossocial (CAPS). É preciso que ela cultive uma experiência compartilhada em torno de seus temas, promovendo abertura e transversalização nas formas pessoais que estes assumem.

No campo da saúde mental, o desafio então é pensar a entrevista como procedimento que enseja a experiência de autonomia coletiva. Para a definição desse procedimento, contamos com algumas contribuições.

Contemporaneamente, nos estudos da cognição, têm sido propostas metodologias para a investigação da espessura complexa da experiência, abrangendo não só a dimensão em que a experiência se apresenta como reflexão pessoal ${ }^{22-}$ ${ }^{24}$. O pressuposto é o de que na base da experiência, sujeito e mundo são inseparáveis, apesar da "atitude natural" (Husserl) que nos faz crer que esses termos são pré-existentes e separados. A compreensão da cognição como fenômeno de criação de si e de mundo - a enação segundo F. Varela - nos leva a distinguir dois aspectos da experiência: a experiência de vida e a experiência pré-refletida ou ontológica ${ }^{25}$. A experiência de vida refere-se a esta vivência cotidiana, que inclui processos motivacionais, emoções, história de vida e reflexões acerca das vivências de um sujeito. Cotidianamente, lidamos com o mundo tal como se o representássemos: tal dimensão de nossa experiência é parte da experiência de vida. Já a experiência pré-refletida ou ontológica é a dimensão da experiência que abrange a coemergência de si e do mundo, dimensão processual ou genética que não se separa da experiência de vida, mas que demanda outros procedimentos metodológicos para que possa ser abordada.

As propostas de instrumentos metodológicos como a "entrevista de explicitação" 26 e a "entrevista cartográfica" 27,28 contribuem para o desafio de investigar a dimensão pré-refletida da experiência. Como conhecer a dimensão processual da experiência na qual coemergem sujeito e mundo? Como pesquisar uma realidade que está em processo de constituição na própria experiência de conhecê-la? Tal desafio metodológico requer que discutamos o manejo da entrevista quando a tomamos como procedimento de colheita de dados. Como colher (e não coletar) dados em uma investigação que se quer como pesquisa-intervenção participativa?

\section{O manejo na entrevista}

A entrevista de explicitação ${ }^{26}$ é uma referência importante para o manejo de uma entrevista voltada para o acesso à experiência e à promoção de autonomia. Esta técnica de entrevista visa permitir a verbalização minuciosa de ações, de acordo com o ponto de vista daquele que a realiza, e não do ponto de vista do seu resultado observável. O modo como a ação se dá raramente está disponível, em todos os seus detalhes, à consciência daquele que a realiza. É muito comum que uma pessoa, quando questionada acerca de um ato que realizou, forneça explicações gerais e justificativas teóricas, mas diga pouco acerca de sua experiência concreta e dos gestos específicos. Mesmo para um perito, por exemplo, um clínico experiente, pode ser muito difícil descrever o modo como constrói um diagnóstico, pois nem sempre seu saber-fazer lhe está disponível de forma consciente ou transmissível a outrem em um diálogo. Voltando-se a essa questão, Pierre Vermersch desenvolveu uma técnica de entrevista para permitir que um saber-fazer se torne consciente para o entrevistado e possa ser colocado em palavras. Esta entrevista busca explorar o processo vivenciado durante o curso da ação, isto é, como ela foi realizada e o que aconteceu enquanto ela era feita. Como tal processo não é uma informação imediatamente disponível nem para o entrevistador nem para o entrevistado, trata-se de uma entrevista não diretiva, que sustenta uma atitude de abertura e de experimentação. Ao invés de perguntas pré-definidas, esta entrevista lança mão de técnicas de relance, sensíveis ao que acontece durante o diálogo com o entrevistado e que buscam evocar sua experiência concreta com questionamentos amplos. A 
verbalização da ação ocorre quando surgem, ao longo da entrevista, falas em posição de palavra encarnada, em que o entrevistado se expressa de forma concreta e vívida (ao invés de falar de modo abstrato, geral e distanciado). Esta técnica de entrevista, portanto, guia de modo não diretivo o entrevistado à sua própria experiência, dispondo de tempo para a emergência de um saber que não está dado de antemão. Trata-se de um modo de fazer entrevista que se distingue bastante de uma coleta de informações.

Essa entrevista assume que, para conhecer uma ação, não basta observar os seus resultados ou mesmo a sua execução; é preciso consultar aquele que a realiza, ouvi-lo acerca do que faz e de como experimenta o processo. No caso de um tema como o do medicamento psiquiátrico, portanto, é preciso consultar aquele que faz uso dele, compreender sua utilização como uma ação acerca da qual pouco saberemos se apenas observamos seus efeitos mais visíveis. Uma entrevista não diretiva e aberta permite que o usuário desses medicamentos possa colocar em palavras o seu saber-fazer, de modo que possamos reconhecer este saber como uma ação, isto é, como uma forma de participação no cuidado e no tratamento.

Considerando o caráter de intervenção da entrevista, tal reconhecimento não é apenas uma constatação, ele é também uma transformação nas formas habituais de lidar com o uso do medicamento psiquiátrico. A entrevista torna-se um instrumento de cultivo dessa transformação. Renault et al. $^{27}$ destacam que a entrevista não apenas descreve uma ação realizada - a descrição é já uma experiência que impõe modulações naquilo que é descrito. Ou seja, a entrevista não é a representação de um dado; ela acompanha a experiência na fala e não a fala sobre uma experiência ${ }^{28}$. Trata-se de uma inflexão distinta daquela da entrevista de explicitação (para a qual há um vivido da experiência a ser descrito durante a entrevista). Aqui, a atitude de abertura e não diretividade está menos a serviço da descrição de um vivido do que do cultivo e da emergência de experiências que podem ser inéditas.

Habitualmente, estamos pouco inclinados a considerar a experiência de uso de medicamentos psiquiátricos como um saber-fazer. Consideramos que o saber a respeito dos medicamentos está, preferencialmente, com quem o prescreve. Sob este ponto de vista, aquilo que o usuário experimenta ao fazer uso dos remédios não é tido propriamente como uma ação. Essa experiência, de ser paciente, traz poucas ocasiões para que o saber-fazer de usuário seja colocado em palavras. A realização de uma entrevista tornase, assim, a oportunidade para a transformação desse ponto de vista. Colocar em palavras a ação de usar os medicamentos não é apenas a transmissão de uma informação; é também a emergência de uma experiência mais autônoma e de uma transformação de si e do mundo. Se a entrevista é também intervenção, é porque a experiência a que ela dá lugar é criadora. A passagem de paciente a usuário não se faz sem uma mudança na paisagem que abrange entrevistador e entrevistado, si mesmo e mundo, quem vê e aquilo que é visto.

Assim, a vivência da entrevista busca abranger a experiência de coemergência de si e de mundo. Em outras palavras, a experiência na entrevista não pode ser localizada na subjetividade do entrevistado, porque o próprio entrevistado se constitui diferentemente ao longo da entrevista. Essa transformação se opera também em tudo o que cerca o entrevistado, incluindo o entrevistador. O mundo do usuário não é mais o mesmo mundo do paciente. Os acontecimentos em cada caso são distintos, bem como as ações que lhe são possíveis. Como veremos mais adiante, as práticas de entrevista coletiva ligadas à GAM, ao colocarem lado a lado a experiência de usuários e trabalhadores dos serviços de saúde mental, permite que eles surjam diferentemente um para o outro, modificando seus pontos de vista, as hierarquias já estabelecidas e os modos de relacionamento habituais. Ora, se a entrevista é não diretiva (pois seu desenrolar não é controlado pelo entrevistador) e faz surgir entrevistado e entrevistador de um novo modo, é porque a experiência a que ela dá lugar não se confunde com os fenômenos subjetivos de cada um dos participantes, vividos de modo estritamente individual ou privado. A experiência da entrevista permite com que os participantes surjam, um para o outro, de um modo singular. Este surgimento coetâneo de si e de mundo acontece a todo momento, mas na entrevista ele pode ser contemplado como tal. Quem observa pode, então, reconhecer-se como corresponsável por aquilo que é observado, assumindo uma posição implicada frente ao que lhe aparece. No mesmo movimento, quem é observado pode sair da posição passiva de quem apenas fornece dados, também se corresponsabilizando com o conhecimento produzido. Reconhecer esta participação na experiência tem desdobramentos: está aberto o caminho a uma participação cidadã no tratamento, na rede de saúde mental e na defesa da saúde pública. 
As práticas de entrevista podem, assim, estar afinadas com as de fomento à autonomia nos mais diversos campos. Entendemos que, na saúde mental, a entrevista é uma grande aliada, como no caso da GAM.

\section{O caso Gam}

Reconhecendo o contexto de utilização pouco crítica dos medicamentos nos tratamentos em saúde mental, foi criada no Canadá, nos anos 90, uma nova abordagem de intervenção denominada Gestão Autônoma da Medicação (GAM) ${ }^{29}$. Ela é norteada por princípios que valorizam a autonomia e o protagonismo dos usuários de psicofármacos, a sua qualidade de vida, os seus direitos e o reconhecimento das significações plurais da medicação. A GAM apoia-se na experiência singular do usuário como meio de incluir o ponto de vista de quem vivencia os efeitos de psicofármacos $^{30}$.

A partir de 1999, a realização de um projeto piloto envolvendo dez serviços alternativos no Canadá ensejou a publicação do Guia de Gestão Autônoma da Medicação - Mon guide personel (Meu Guia Pessoal). Seu intuito era viabilizar "uma ferramenta concreta, organizada para auxiliar as pessoas que querem empreender uma reflexão a respeito de sua medicação para chegar a uma qualidade de vida mais satisfatória"29.

A partir de 2009, um projeto multicêntrico chamado Pesquisa avaliativa de saúde mental: instrumentos para a qualificação da utilização de psicofármacos e formação de recursos humanos (CNPq), coordenado por Rosana Onocko Campos, e envolvendo UNICAMP, UFF, UFRJ, UFRGS e Universidade de Montreal se dedicou a traduzir, adaptar e testar o Guia de Gestão Autônoma da Medicação (Guia GAM) para o contexto brasileiro $^{31}$. A versão brasileira foi construída por meio da realização de Grupos de Intervenção (GI) em CAPS dos estados de São Paulo, Rio de Janeiro e Rio Grande do Sul. Os GI são grupos de leitura e discussão coletiva do Guia em sua versão adaptada e contam com a participação de usuários, trabalhadores e pesquisadores. No ano de 2011, no Rio de Janeiro, foi realizada uma nova etapa da pesquisa-intervenção. O projeto Autonomia e direitos humanos: validação do guia de gestão autônoma da medicação (GAM), realizado por pesquisadores da UFF sob a coordenação de Eduardo Passos, objetivou a validação dessa versão adaptada do Guia. Para tanto, novos grupos de intervenção foram realizados em um CAPS no interior do Estado, desta vez contando tam- bém com um GI com familiares de usuários, trabalhadores e pesquisadores.

As apostas desta pesquisa-intervenção estão em sintonia com o modo de entrevistar a que vínhamos nos referindo. A partir de nossas considerações acerca da entrevista, entendemos a realização do grupo GAM como uma prática de entrevista coletiva. O próprio Guia GAM se constitui por perguntas abertas, questionamentos amplos a respeito de ações cotidianas bem específicas (Como é tomar os remédios? Como você cuida de onde vive? Com quem você pode contar nos momentos difíceis?). Interessa menos ao grupo GAM obter as informações que responderiam corretamente a essas perguntas do que promover o compartilhamento e a coletivização de experiências acerca desses temas. Nesse sentido, o grupo GAM é uma entrevista coletiva, na qual os participantes dispõem de tempo para explorar as questões e novas experiências acerca do uso de psicofármacos podem emergir. O manejador do grupo, tal como um entrevistador, guia de maneira não diretiva a colocação em palavras dessas experiências, acompanhando esse processo de coletivização. Nesse sentido, o grupo GAM promove a prática cogestiva da medicação (manejo cogestivo), apostando na participação dos diferentes sujeitos com seus pontos de vista implicados no processo de produção de saúde.

Esse manejo distingue o grupo GAM de um focal, com o qual ele não poderia ser confundido. Os grupos focais constituem um tipo de entrevista em grupo que valoriza a comunicação entre os participantes ${ }^{10,32}$. Estes são estimulados pelo manejador do grupo a falarem uns com os outros, a trocar comentários e a interagirem a partir de um tema que ajuda a focar e a provocar o debate. Nos grupos GAM, os temas relativos ao uso do medicamento são apresentados pelo Guia GAM. Contudo, não se realiza aqui um manejo visando à focalização das falas do grupo, o que poderia envolver a restrição do espectro da discussão. Os temas do Guia GAM têm a função de ativar o plano problemático do uso do medicamento, ampliando a experiência do coletivo. $\mathrm{O}$ que o manejo dos grupos GAM foca serve na verdade para intensificar os graus de abertura da discussão, de maneira a fazer emergir dimensões da experiência do uso de psicofármacos que deslocam os pontos de vista inicialmente dados. Essa especificidade distingue o grupo GAM de um grupo focal, pois seu manejo precisa acompanhar não apenas o foco da discussão, mas também o fora-foco. Segundo Kastrup ${ }^{33}$, a investigação dos processos de criação exige uma atitude atencio- 
nal que circule do foco da atenção às suas margens, lá onde nos deparamos com fluxos de sensações e componentes aformais refratários à representação. Com esse trânsito, a entrevista coletiva pode seguir rotas inventivas, movidas por pensamentos fora de lugar, percepções sem finalidade, reminiscências vagas, objetos desfocados e ideias fluídas. O manejo com o fora-foco permite aos grupos GAM incluir falas que aparentemente indicam desvios ou incongruência em relação ao tema e colocar lado a lado pontos de vistas distintos. O manejo, assim, vai além da interação entre os participantes em torno de um tema, para pôr em cena a transversalidade das relações, pois a entrevista coletiva no grupo GAM fomenta, ao mesmo tempo, a criação de novas perspectivas e a coletivização da experiência.

Quando consideramos o aspecto coemergente da experiência na entrevista podemos perceber que já há uma experiência coletiva na base desses movimentos de coletivização. Esta experiência coletiva não se dá apenas por um somatório de indivíduos, nem tão somente por um reconhecimento identitário do grupo. Ela é uma experiência de compartilhamento e de pertencimento, que é condição para a emergência de novas identidades.

Nos grupos GAM pudemos perceber alguns desses efeitos que nos permitem caracterizá-los como entrevistas coletivas. Nos grupos realizados com os usuários e trabalhadores do CAPS em 2011, o tema da identidade era recorrente. Logo no início do trabalho, durante a realização dos primeiros grupos, o Guia propõe questões acerca desse tema: "Como você se apresenta?"; "Como os outros apresentam você?". Uma participante responde: "Sou boa, honesta, linda e... explosiva”. O grupo cai em gargalhada, mobilizado pela autodescrição da participante. "Mas como assim, explosiva?", pergunta o manejador. A participante passa então a narrar diversas situações em que se sentia discriminada, como quando lhe negavam acesso a consultas em serviços de saúde geral. "Tratam a gente como deficiente”, ela dizia. Implicitamente, percebia-se o quanto ser tratado assim é revoltante e que, às vezes, é difícil não explodir. Sua narrativa, no entanto, não era incompatível com outros sentidos, que admitiam posições afirmativas de outros, como quando pessoas a deixavam passar à frente na fila do mercado. Havia uma atitude respeitosa, experimentada como acolhimento. Durante um tempo, o grupo se debruça nessas questões, quando surge então uma nova inflexão: outra participante toma a fala, em tom de exaltação. "Não sou indiferente coisa nenhuma!", ela diz. Ela narra a experiência de sentir-se ignorada ou tratada como ignorante. Diz saber e entender sua condição: era "esquizofrênica desde os 14 anos", mas isso não fazia dela uma pessoa indiferente. Novamente, afirmava-se um duplo sentido, ao mesmo tempo negativo e positivo, de revolta e de resistência. E no meio das identificações, a possibilidade de afirmar-se diferentemente. "Não sou indiferente", quer dizer justamente isto: sou diferente.

As respostas foram sendo moduladas conforme a conversa transcorria. Fazer parte dos grupos GAM não era, assim, fornecer informações a respeito de uma identidade prévia do tipo "ser deficiente" ou "possuir tal diagnóstico". Era a possibilidade de surgir diferentemente em um grupo, compartilhar experiências que permitissem ver e ser visto de formas diferentes, singulares. O manejo das entrevistas coletivas ou grupos GAM permitia com que o acolhimento e a emergência de novas experiências fossem um só e mesmo gesto. Na sequência dessas conversas, em um encontro com o grupo, uma usuária fez a proposta: os participantes do grupo GAM poderiam ter uma camiseta que os identificasse. Uma nova identidade, até então inexistente, estava surgindo e, com ela, novos modos de se relacionar em grupo. Também esta identidade pôde passar por modulações ao longo das entrevistas, tendo sido colocada em questão para permitir o acolhimento das diferentes formas de participação no grupo, bem como a entrada de novos participantes. Contudo, consideramos um importante indicador de sucesso das entrevistas o estranhamento de uma identidade que surgia como dada e a possibilidade de formular uma proposta com base em uma nova percepção de si e do mundo.

Na sequência dessas conversas acerca de identidades e das possibilidades de pertencimento a um grupo, o Guia propõe uma pergunta: "Como você cuida de si mesmo?” Aos poucos, foram surgindo diversas falas dos usuários contando como cuidavam de si mesmos, seja cuidando da higiene pessoal, seja buscando brincar e se divertir. Um usuário pôde contar que sofria com a vontade de querer saber as coisas e que os pensamentos e dúvidas lhe ocorriam de forma excessiva, lhe causando aflição. Uma forma que ele utilizava para cuidar de si mesmo era procurar tirar suas dúvidas. Sua estratégia de cuidado de si consistia em esperar alguns instantes após a experiência de certa dúvida e, alguns minutos depois, verificar se a dúvida persistia ou se tinha ido embora. Essa forma de cuidado não estava imediatamente disponível como uma resposta abs- 
trata ou geral para a pergunta "Como você cuida de si mesmo?”. Sua resposta expressava uma atitude singular e concreta, um gesto que não pode ser conhecido sem que consultemos a experiência de quem o faz e sem criar as condições para a formulação do sentido singular de cuidado que esse usuário experimentava. A resposta à pergunta "Como você cuida de si mesmo?" derivou das condições de emergência propiciada pelo grupo, encarnando a experiência do usuário, o que difere de uma resposta geral e distanciada como “eu me cuido tomando remédios”, por exemplo.

Ora, se os grupos GAM são entrevistas coletivas, o surgimento de uma resposta como essa não é apenas a transmissão de uma informação. Foi isso que esse usuário nos mostrou ao longo deste mesmo encontro. Depois de responder à questão, esse usuário compartilhou com o grupo suas respostas a outra pergunta do Guia: "O que você gostaria de fazer e não faz?”. Ele contou ao grupo dificuldades que enfrentava em sua vida e situações que o deixavam constrangido, isto é, que dificilmente ganhavam expressão diante de outras pessoas. $\mathrm{O}$ grupo pôde acolher sua experiência e outros também contaram suas dificuldades e apreensões. Ao final da conversa, o usuário se dirigiu ao entrevistador/manejador do grupo e disse: "olha só, eu achava que esse grupo era para descobrir o diagnóstico da gente e curar a gente, mas aí eu percebi que não, que é para ajudar a gente também”. Nesta sua fala, há a emergência de um novo sentido para o grupo. $\mathrm{O}$ grupo lhe surge de uma forma inesperada, permitindo que ele próprio também se posicionasse diferentemente frente aos integrantes. Há uma dimensão de surpresa em sua fala, indicando que uma experiência nova estava surgindo para ele. A qual lhe esclarecia em relação ao que era o grupo GAM, com o qual ele se sentia à vontade para compartilhar experiências. Neste momento, para o usuário, há uma distinção que até então não havia sido colocada em palavras no grupo, entre o diagnóstico ou cura e ajuda. Em sintonia com a discussão do Guia, o usuário pôde formular a distinção existente entre o uso do medicamento e o cuidado, concebido de forma ampliada. Acompanhando esta possibilidade de formulação, está o movimento de compartilhamento e coletivização de questões. Os grupos GAM puderam proporcionar reposicionamentos subjetivos diante de certos temas e a valorização de experiências que dificilmente podiam ser colocadas em palavras ou reconhecidas por outrem.

\section{O coletivo como efeito da entrevista}

O manejo na entrevista coletiva caracterizase por uma orientação não diretiva que "deixa vir" (letting go) a experiência, na mesma medida em que cria um plano de coparticipação e corresponsabilidade dos mundos que coemergem. Tomada em sua radicalidade, esta orientação eleva a experiência do entrevistar a seu limite, até o ponto em que as experiências do(s) entrevistado(s) e do entrevistador, embora distintas, não admitem mais separação, passando ambos a participar de um mesmo plano genético, o qual designamos de plano comum.

É este plano que a entrevista coletiva procura acessar, entendendo que a explicitação de atos e processos pré-refletidos que ela promove não acontecem sem a produção de novos pontos de vista, performatizados na situação social que ela cria. É preciso dizer que, nesta situação, os pontos de vista emergem em relação a um conjunto de referências: modos de se referir a si mesmo e ao mundo na relação com aquele a quem se refere. A fala encarnada não apenas descreve uma realidade vivida, mas produz e diferencia as vivências em função da qualidade do vínculo e da referência ao outro no grupo. Ela realiza um aumento da abertura comunicacional, mas em um plano onde a comunicação se dá menos por troca de informação do que por compartilhamento do sentido, na dupla acepção do termo: aquilo que é sentido e aquilo que faz sentido, isto é, o sensível e o semântico. Como fenômenos exteriores e coletivos, os posicionamentos e reposicionamentos possibilitados pela fala encarnada na entrevista coletiva são inseparáveis dos processos de produção social do sentido.

Pôr a experiência em palavra não é apenas externalizar o que me habita de maneira isolada, íntima e pessoal: a explicitação de atos e processos vividos de maneira privada não constitui a finalidade da entrevista, mas o seu meio. Por meio da explicitação, aquilo que é sentido de maneira isolada e pessoal passa a habitar um plano comum, plano de compartilhamento da experiência, que instaura uma "partilha do sensível”, para falar como Jacques Rancière. Por partilha do sensível Rancière entende o processo de constituição estética que dá forma à comunidade, encarado do duplo ponto de vista da partilha: "a participação em um conjunto comum e, inversamente, a separação, a distribuição dos quinhões" ${ }^{34}$. O modo de relacionar o comum partilhado e as 
partes exclusivas é decidido em uma ordem política, incluindo aí as batalhas concernentes às muitas maneiras de redistribui-los.

Ao propiciar o acesso ao plano comum, acolhendo as diferentes colorações e entoações da experiência em um mesmo território de partilha, a entrevista coletiva orienta-se pelo acompanhamento das modulações da experiência que, mesmo imperceptivelmente, atravessa as sucessivas falas. As muitas ações e paixões que nos habitam virtualmente em um domínio pré-refletido não são menos pertencentes a este domínio comum, zona impessoal e pré-individual da subjetividade, ao mesmo tempo aquém e além do indivíduo (o infraindividual das sensações e afetos e o supraindividual das ações coletivas).

No grupo GAM a experiência narrada não pode ser referida simplesmente ao indivíduo que narra, como centro e sujeito de enunciação. É notável que as narrativas acerca da experiência pessoal com o medicamento quase sempre surjam acompanhadas dos muitos pontos de vista alheios incorporados à experiência pessoal: "Ela disse assim: você tem que tomar esse remédio pra ficar boa, mas o pastor disse que não era pra tomar e eu ficava me perguntando o que era o certo, o que Deus queria pra mim", diz uma participante. Considerar a coexistência dos múltiplos pontos de vista na experiência da entrevista coletiva tem consequências importantes, como veremos, para a condução e a análise dos dados colhidos na entrevista.

Dependendo de como tomamos o enunciado, é possível a referência a diferentes instâncias de enunciação. Tomado no domínio estrito do indivíduo, o enunciado referencia-se em uma subjetividade isolada e pessoal, pressupondo autoria única. O domínio do comum é aí atrofiado e relegado aos recônditos pré-refletidos da experiência pessoal, transformada em centro de enunciação. Mas não será possível encontrar outro modo de tomar as falas na experiência?

No grupo formado por usuários e trabalhadores, a apropriação das temáticas ofertadas pelo Guia ("autonomia", "cuidado compartilhado", "reforma psiquiátrica", "atenção psicossocial” etc.) conduziu não raro a uma experiência de modulação contínua do sentido de cada tema. O sentido da autonomia, por exemplo, foi tomado inicialmente sob certa surpresa e estranhamento. O primeiro entendimento gerado sobre o termo fazia referência a quem trabalha por conta própria, a quem não tem patrão ("trabalhador autônomo”), como se a autonomia não fizesse, a princípio, parte do universo do cuidado em saúde mental, já que frequentemente os usuários do CAPS não têm trabalho formal. Este sentido de autonomia, no entanto, possibilitou a emergência de outros mais próximos do universo dos usuários: a capacidade de tomar os medicamentos sem ajuda de alguém e a de fazer escolhas independentemente do acompanhamento profissional ("automedicação"). O primeiro sentido trazia a insatisfação de alguns frente à demasiada dependência a outras pessoas, pelo fato, por exemplo, de frequentemente os usuários confundirem comprimidos ou de não conseguirem contar o número de gotas de certo medicamento. $\mathrm{O}$ segundo sentido, por sua vez, expunha um problema vivido no cotidiano do serviço e que recaía sobre o Guia com certa desconfiança: o Guia estaria propondo a automedicação? Alguns participantes admitiram que, em certos momentos e por certas razões, já haviam praticado a automedicação, o que gerou forte reação de supervalorização da prescrição médica no grupo, assumindo que "ele [o médico] é quem estudou, ele é quem sabe". Ao lado desta postura obediente, contudo, falas descontínuas mantiveram posições minoritárias, que consistiam em reivindicar uma posição ativa na determinação do tratamento medicamentoso. Em certo momento, o grupo pôde formular uma questão que passou a ser continuamente recolocada: qual o lugar da escolha do usuário em saúde mental no que diz respeito aos medicamentos que usa?

No que diz respeito à condução, a atitude de abertura da entrevista coletiva acolhe os pontos de vista que emergem sem, contudo, se fixar em nenhum deles: o manejo relança as falas para a experiência do grupo, propiciando outra partilha do sensível, nem consensual, nem segregadora, mas inclusiva. Os sentidos emergem na entrevista juntamente a certa experiência de indeterminação, pela recusa a decretar de fora a última palavra sobre o tema. Como efeito, no exemplo citado, o sentido da autonomia entra em modulação, suspende determinações estanques e equivoca os nexos que sustentam práticas concretas quer de extrema dependência, quer de total independência do outro. Embora o acesso a tais experiências exponha a marca da heteronomia no cuidado em saúde mental, verificou-se que a lateralização das relações de sujeição, de resistência e de subversão criou condições para outra relação de partilha do sensível, mais inclusiva e corresponsável.

Do ponto de vista da análise, o acesso a este plano comum torna possível traçar uma linha narrativa que percorre os discursos, que interliga 
as falas, mesmo quando não diretamente associáveis, tomando-as em um vínculo responsivo que conecta as experiências subjetivas numa mesma enunciação coletiva e polifônica. Não se trata, no entanto, de reconhecer uma instância enunciativa que rebate sobre o grupo a forma do sujeito, mas de um movimento sem direção pré-definida, de um processo de subjetivação que conecta os indivíduos e imprime-lhes um movimento de diferenciação, sem entretanto totalizar um novo centro de enunciação. Por isto a narrativa que deriva do grupo GAM tem um traçado polifônico: não suprime nenhum sentido, mas coloca-os lado a lado, num mesmo plano de consistência.

O acesso ao plano comum na entrevista coletiva é inseparável de dois processos: 1) o movimento de contração de grupalidade, como processo que funda um presente vivo compartilhado no grupo; 2) o traçado que articula as enunciações particulares em um mesmo processo coletivo de enunciação do grupo e para o grupo. $\mathrm{Na}$ pesquisa, o acesso ao plano comum não se faz de um só golpe, mas no revezamento destes dois momentos do processo de intervenção, de direito inseparáveis: condução in loco da entrevista e análise processual de seus efeitos. A experiência do/no grupo se desdobra e continua na experiência da análise de seus efeitos, se enriquecendo por ela, de modo que a análise do processo de intervenção se faz com o grupo.

Desta forma, o plano comum não é apenas um pressuposto da entrevista, mas também seu efeito. Acessar o plano é também traçá-lo. Não se trata de explicitar sentidos prontos, já dados, mas de traçar as condições coletivas para diferir de si. Eis porque entendemos que a promoção de autonomia, como diretriz ético-política da GAM, é inseparável do traçado deste plano comum, em que o processo de constituição de suas próprias regras (nomos) não se faz isoladamente, mas coletivamente, em relação com os diferentes pontos de vista que compartilham uma mesma experiência. O autos da palavra autonomia, não diz respeito necessariamente ao que é próprio do indivíduo, ao que é da ordem do pessoal, mas se define como a propriedade emergente de um coletivo.

Como ponto nodal do tratamento em saúde mental, o medicamento não concerne apenas à experiência do usuário de psicofármacos, mas também à de quem prescreve e à de quem acom- panha, bem como, de maneira mais ampla, a toda a comunidade. Não raro, a explicitação da experiência com o medicamento traz à tona a qualidade dos vínculos estabelecidos com a comunidade como um todo, os diversos pontos de vista que se referem ao "paciente" ora como doente, ora como deficiente, ora como especial, ora como louco etc. A posição de usuário não está dada a priori: ela precisa muitas vezes ser gestada em meio às oscilações do sentido de pertencimento à comunidade, incluídas aí a qualidade do reconhecimento de experiências relegadas via de regra à doença orgânica ou à loucura.

Os modos de ver e significar a realidade, os modos de fazer e de dizer veiculados nos serviços podem dar mais ou menos chances para um processo de emergência e transversalização dos pontos de vista, de corresponsabilização na promoção da saúde e de autonomização dos grupos. Como estratégia metodológica da produção de conhecimento no campo da saúde, a pesquisa-intervenção participativa enfatiza o cultivo dos dados em um processo de coautoria do conhecimento que se produz colocando lado a lado pesquisadores e participantes. Ao apresentarmos a GAM como entrevista coletiva, procuramos mostrar como a produção de conhecimento em saúde alia-se à consolidação dos princípios da Reforma Psiquiátrica brasileira, pautados na atenção psicossocial, na promoção da autonomia, na protagonização do usuário e na ampliação da rede de relações. Pesquisar a GAM é colocá-la para funcionar.

A estratégia GAM, no Brasil, busca criar condições para que a gestão dos medicamentos psiquiátricos possa incluir os diferentes pontos de vista em um mesmo processo de compartilhamento dos mundos que coemergem nas práticas de cuidado dos serviços. Trata-se de adotar a cogestão como estratégia de abordagem das questões, colocando lado a lado usuários e trabalhadores do serviço. Na medida em que os modos instituídos de referir-se a si, ao mundo e ao outro dão lugar a uma pluralidade de referências no grupo, ampliando a rede de vínculos com corresponsabilidade, uma nova partilha torna-se possível. E com ela, a conversão a ser sempre exercitada, re-efetuada, que transforma o paradigma da alta - a cura como direção do tratamento - no paradigma do autos - a autonomia coletiva como produção de saúde. 


\section{Colaboradores}

C Sade, LMR Barros, JJM Melo e E passos participaram igualmente de todas as etapas de elaboração do artigo.

\section{Agradecimentos}

Este trabalho foi realizado com apoio da Faperj.

\section{Referências}

1. Passos E, Benevides R. A cartografia como método de pesquisa-intervenção. In: Passos E, Kastrup V, Escóssia L, organizadores. Pistas do método da cartografia: pesquisa-intervenção e produção de subjetividade. Porto Alegre: Sulina; 2009. p. 17-31.

2. Rocha M, Aguiar K. Pesquisa-Intervenção e a produção de novas análises. Psic Cien Prof 2003; 23(4): 64-73.

3. Despret V. The body we care for: figures of antropo-zoo-genesis. Body Society 2004; 10(2-3):111-134.

4. Latour B. A esperança de Pandora. São Paulo: EDUSC; 2001.

5. Stengers I. A invenção das ciências modernas. São Paulo: Ed. 34; 1993.

6. Lourau R. Análise Institucional e Práticas de Pesquisa. Rio de Janeiro: UERJ; 1993.

7. Altoé S, organizadora. Rene Lourau: analista institucional em tempo integral. São Paulo: Hucitec; 2004.

8. Britten N. Entrevistas qualitativas. In: Pope C, Mays N. Pesquisa qualitativa na atenção à saúde. Porto Alegre: Artmed; 2009. p. 23-31.

9. Fraser MTD, Gondim SMG. Da fala do outro ao texto negociado: discussões sobre a entrevista na pesquisa qualitativa. Paideia 2004; 14(28):139-152.

10. Gaskell G. Entrevistas individuais e grupais. In: Bauer M, Gaskell G, organizadores. Pesquisa qualitativa com texto, imagem e som: um manual prático. Petrópolis: Vozes; 2005. p. 64-89.

11. Fontanella BJB, Campos CJG, Turato ER. Coleta de dados na pesquisa clínico-qualitativa: uso de entrevistas não-dirigidas de questões abertas por profissionais da saúde. Rev Lat Am Enf [periódico na Internet]. 2006 set-out [acessado em $2012 \mathrm{dez}$ 20];14(5): [cerca de 10p.]. Disponível em: http:// redalyc.uaemex.mx/src/inicio/ArtPdfRed.jsp?iCve $=281421864025 \#$

12. Benevides R, Passos E. A humanização como dimensão pública das políticas de saúde. Cien Saude Colet 2005; 10(3):561-571.

13. Benevides R, Passos E. Humanização na saúde: um novo modismo? Interface (Botucatu) 2005; 9(17):389394.

14. Brasil. Ministério da Saúde (MS). Secretaria de Atenção à Saúde. Política Nacional de Humanização da Saúde. Documento Base. 4a Edição. Brasília: MS; 2007.

15. Campos GW. Um método para análise e co-gestão de coletivos. São Paulo: Hucitec; 2000

16. Guattari F. A transversalidade. In: Guattari F. Psicanálise e transversalidade: ensaios de análise institucional. Aparecida: Ideias e Letras; 2004. p. 75-84.

17. Benevides R, Passos E. Transversalizar. In: Galli TM, Nascimento L, Maraschin C, organizadoras. Pesquisar na diferença: um abecedário. Porto Alegre: Sulina; 2012. p. 239-242.

18. Leal EM. Clínica e subjetividade contemporânea: a questão da autonomia na Reforma Psiquiátrica brasileira. In: Figueiredo AC, Cavalcanti MT, organizadores. A reforma psiquiátrica e os desafios da desinstitucionalização. Rio de Janeiro: Ipub, Cuca; 2001. p. 69-83.

19. Eirado A, Passos E. A noção de autonomia e a dimensão do virtual. Psic Estud 2004; 9(1):77-85. 
20. Kinoshita R. Contratualidade e Reabilitação Psicossocial. In: Pitta A, organizadora. Reabilitação Psicossocial no Brasil. São Paulo: Hucitec; 1996. p. 5559.

21. Deleuze G, Parnet C. Diálogos. São Paulo: Escuta; 1998.

22. Varela F, Shear J. First-person accounts: why, what, and how. J Consc Stud 1999; 6(2-3):1-14.

23. Depraz N, Varela F, Vermersch P. On Becoming Aware. Amsterdam, Philadelphia: John Benjamins Publishing Company; 2003.

24. Petitmengin C, organizadora. Ten years of The Viewing from within: the legacy of Francisco Varela. Charlottesville: Imprint Academic; 2009.

25. Eirado A, Passos E, Fernandes CVA, Guia FR, Ratto F, Carvalho JF, Barros LMR, Vasconcelos CS. Estratégias de pesquisa no estudo da cognição: o caso das falsas lembranças. Psic Soc 2010; 22(1):84-94.

26. Vermersch P. L'entretien d'explicitation. Issy-lesmoulineaux: ESF; 2000.

27. Renault L, Passos E, Eirado A. Da entrevista de explicitação à entrevista na pesquisa cartográfica. In: Amador FS, Barros MEB, Fonseca TMG, organizadoras. Clínicas do trabalho e paradigma estético. Editora UFRGS. No prelo 2012.

28. Tedesco S, Sade C, Caliman L. A entrevista na pesquisa cartográfica: a experiência do dizer. Fractal. No prelo 2013.

29. RRASMQ-ÉRASME. Repères pour une Gestion autonome de la médication en santé mentale. Guide d'accompagnement. Montréal: RRASMQ-ÉRASME; 2006.

30. Rodriguez L, Corin E, Poirel ML. Le point de vue des utilisateurs sur l'emploi de la médication en psychiatrie: une voix ignorée. Rev québécoise de psychol 2001; 22(2):201-223.

31. Onocko Campos R, Palombini A, Silva A, Passos E, Leal E, Serpa O, Marques C, Gonçalves L. Adaptação multicêntrica de um Guia para a Gestão Autônoma da medicação. Interface (Botucatu) 2012; 16(43):967-980.

32. Kitzinger J. Grupos focais. In: Pope C, Mays N. Pesquisa qualitativa na atenção à saúde. Porto Alegre: Artmed; 2009. p. 33-43

33. Kastrup V. A aprendizagem da atenção na cognição inventiva. Psic Soc 2004; 16(3):7-16.

34. Rancière J. Políticas da escrita. Rio de Janeiro: Ed 34; 1995.

Artigo apresentado em 15/03/2013

Aprovado em 20/03/2013

Versão final apresentada em 25/03/2013 